\title{
Algumas contribuições da psicanálise à educação a partir dos conceitos de transferência e discurso
}

\section{Some contributions from psychoanalysis to education from the concepts of transference and speech}

\author{
Rosa Maria Marini Mariotto ${ }^{1}$
}

\begin{abstract}
RESUMO
Partindo da suposição de que a relação pedagógica está implícita na relação humana, a educação se desenvolve muito mais pelo laço que se estabelece do que pelo conhecimento adquirido que expressamos ao outro. Desse modo, este artigo pretende investigar algumas contribuições que pode a psicanálise oferecer ao campo da educação, circunscrevendo primeiramente a temática da transferência no sentido de refletir sobre o laço professor-aluno para, em seguida, apresentar o conceito proposto por Lacan de discurso e suas modalidades, articulando-o com o fato de que nos laços estabelecidos entre a educação, as ciências, os educadores e os educandos, o discurso faz giro; nunca permanece numa única modalidade discursiva, interferindo na aprendizagem.
\end{abstract}

Palavras-chave: educação; aprendizagem; psicanálise; transferência e discurso.

\begin{abstract}
Starting from the assumption that the pedagogical relationship is implicit in human relationships, education develops much more by the bond established than by the acquired knowledge that we express to the other. In this way, this article intends to investigate some contributions that psychoanalysis can offer to the field of education. First circumscribing the transference
\end{abstract}

DOI: $10.1590 / 0104-4060.49816$

1 Fundação de Amparo à Pesquisa do Estado de São Paulo. São Paulo, São Paulo, Brasil. Rua Pio, XI, nº 1500. Alto da Lapa. CEP: 05468-140.E-mail: rosamariotto@uol.br 
concept in order to reflect upon the teacher-student tie, and, next presenting the concept of discourse and its modalities proposed by Lacan. This concept articulates with the fact that, considering the bonds among education, sciences, educators and learners, the discourse makes turns; it never remains in a single discursive mode, interfering in learning.

Keywords: education; learning; psychoanalysis; transference and speech.

\section{Introdução}

Em 1925, Freud, prefaciando o livro a Juventude Desorientada de Aichorn, vaticinava que nenhuma das aplicações da psicanálise excitou tanto interesse e despertou tantas esperanças, quanto seu emprego na teoria e prática da educação. (FREUD, 1925).

Ainda que não tenha publicado um texto específico a respeito da educação, esse tema sempre esteve presente em Freud. Como exemplo, citamos o texto de 1927, O futuro de uma ilusão, que é, por muitos, considerado seu testamento pedagógico. Nesse tempo de suas reflexões, ele define que a finalidade da educação é a instauração do princípio de realidade, ajudando a criança a renunciar ao seu modo de funcionamento quase todo submetido ao princípio do prazer. Sendo assim, o ato educativo se refere à inscrição de marcas que operam a passagem de pura satisfação das pulsões para um universo simbólico onde a lei, representada pela palavra do Outro, introduz o futuro sujeito ao "civilizado". Dessa forma, entendemos que todo ato educativo refere-se a operações de transmissão - de um legado, de um saber, de um desejo -, e de transformação - da carne, ao sujeito.

No entanto, durante um bom período, essa interlocução parece ter ficado em latência. De acordo com Kupfer et al. (2010) o campo dessa articulação se retraiu por quase quarenta anos, inclusive com o encerramento em 1937 da Revista de Pedagogia Psicanalítica, editada em Viena desde 1926. Não é coincidência que o fechamento dos trabalhos da revista seja também o de publicação do artigo Análise terminável e interminável, em que o psicanalista reconhecia os limites de uma aplicação da psicanálise à educação.

Contrariamente, vivemos atualmente um tempo de importantes contribuições de autores psicanalíticos em relação ao tema, que vem ganhando cada vez mais corpo e consistência, principalmente a partir da década de 1980. (KUPFER et al., 2010).

Mas, por quê? Que razões justificam esse interesse, essa esperança renovada nesse diálogo (im)possível? 
Uma delas é clássica. E é em Freud que a encontramos também: "Em um primeiro estádio, aceitei o bon mot que estabelece existirem três profissões impossíveis - educar, curar e governar -, e eu já estava inteiramente ocupado com a segunda delas". (FREUD, 1925; 1937, p. 341). Submeter educar e curar (ou psicanalisar) ao status de profissão impossível já é um grande motivo para que os psicanalistas se debrucem sobre essa "pequena" semelhança, porém, sempre com o compromisso ético de vislumbrarem o abismo que separa a posição do analista e o lugar do educador. Isto é, se por um lado, tanto educar quanto psicanalisar leva o praticante à dura constatação de que não se educa tudo nem se cura tudo, por outro, o lugar de onde se faz operar esse impossível é completamente distinto um do outro.

Sendo assim, o objetivo deste trabalho é duplo. Em primeiro plano trataremos de apesentar algumas contribuições que pode a psicanálise oferecer ao campo da educação, circunscrevendo a temática da transferência no sentido de refletir sobre o laço professor-aluno. A noção de transferência - mola mestra do processo psicanalítico segundo Freud - servirá de operador conceitual chave para a compreensão da relação professor-aluno, enquanto um processo correlato. Para que em seguida possamos nos valer do conceito de discurso e suas modalidades, apresentado por Lacan, para refletir a respeito das ressonâncias produzidas ao se considerar o ato educativo e a aprendizagem no discurso do Mestre e no discurso Capitalista.

\section{Transferência e aprendizagem}

Para Freud, educar é transferir um legado de pai para filho. Partindo da suposição de que a relação pedagógica está implícita na relação humana, a educação se desenvolve muito mais pelo laço que se estabelece do que pelo conhecimento adquirido que expressamos ao outro. Nesse sentido, pensar a educação no âmbito do enlaçamento que um faz com o outro exige introduzir a subjetividade num campo em que o saber fazer normalmente se sobrepõe ao saber ser. Exige também extrair do dispositivo conceitual da transferência elementos que nos auxiliem nessa reflexão.

Em seus artigos sobre a técnica, mais especialmente em a Dinâmica da Transferência (1912), vemos Freud elevando esse conceito ao status de motor do tratamento psicanalítico, permitindo, por meio da fala, a reorganização do modo de funcionamento psíquico. Mas já em 1901 encontramos uma valiosa definição de transferência: 
[...] reedições dos impulsos e fantasias despertadas e tornadas conscientes durante o desenvolvimento da análise e que trazem como singularidade a substituição de uma pessoa anterior pela pessoa do médico. (FREUD, 1901, p. 998).

Damos destaque aqui para a ideia de que a figura que pode ser a substituta nessa operação transferencial é o professor. Assim, o professor é convocado a ocupar um lugar que transcende a prática pedagógica, na medida em que se torna suporte dos investimentos libidinais de seu aluno, já que é objeto de uma transferência. Mais além da figura pessoal do professor, o educador vai representar, para o aluno, uma função, substituindo, nesse momento, as figuras parentais e/ou pessoas que lhe foram importantes, representando então esse lugar de saber, de idealização e de poder. Implica, portanto, em uma relação afetiva $\mathrm{e}$, por isso, sempre ambivalente.

Em um sensível texto de Freud, ele nos mostra de modo quase poético essa questão:

No fundo, sentíamos grande afeição por eles, se nos davam algum fundamento para ela, embora não possa dizer quantos se davam conta disso. Estávamos, desde o princípio, igualmente inclinados a amá-los e a odiá-los, a criticá-los e a respeitá-los. (FREUD,1914, p. 286).

Ora, aprender supõe sempre aprender com alguém. Esse que ensina será sempre colocado pelo aluno numa determinada posição que pode ou não proporcionar a aprendizagem, indicando que o lugar que o aluno o coloca não é apenas o daquele que ensina. É o desejo inconsciente desse aluno que está determinando o lugar a ele conferido, como uma espécie de tela onde serão depositadas projeções alheias a ele enquanto pessoa.

Seguindo esse raciocínio, concordamos com Nunes que afirma que a autoridade do professor não é imposta ao aluno, mas outorgada ao professor pelo próprio aluno. (NUNES, 2004). Podemos observar, então, que o conceito de transferência traz de arrasto a questão do poder e autoridade que são investidos no professor a partir do aluno, e também a de desejo tanto do aluno quanto do professor.

Somente se o professor ocupar esse lugar de saber que sua palavra terá poder suficiente para ser ouvida pelo aluno como algo que anime seu interesse. Não adiantam as técnicas pedagógicas mais atuais, o aparato tecnológico mais 
moderno se esse pequeno detalhe não estiver em jogo. Da educação infantil à universidade, a transferência torna-se a mola propulsora do processo ensino-aprendizagem.

Discutimos mais profundamente a questão da função do educador no campo da educação infantil em outro trabalho (MARIOTTO, 2009), mostrando a importância do outro na educação de bebês. Essa reflexão, porém, nos permite entender o que se passa no processo de aprendizagem de modo geral a partir da noção de discurso para a psicanálise, com as respectivas considerações lacanianas, buscando argumentar o modo como o educador pode enlaçar discursivamente seu aluno a partir do que Lacan define como discursos do mestre, do universitário e do capitalista, observando a partir daí os efeitos no processo de aprendizagem.

\section{Discurso e aprendizagem}

Lacan (1969-1970) trabalhou extensamente os chamados quatro discursos em seu Seminário $O$ Avesso da Psicanálise. Se, para ele, o inconsciente está estruturado como uma linguagem, localizamos que sua manifestação só se dá sob forma discursiva. Além disso, revela que um sujeito atravessado pela linguagem somente o é na condição de ser amarrado no laço com o outro. Sendo assim, a forma pela qual os sujeitos tecem e estruturam seus laços transferenciais define a ideia lacaniana de discurso.

Entendemos que Freud (1930) abre caminho para esse raciocínio quando discute os atos de governar, psicanalisar e educar em seu trabalho Mal-estar na civilização e no prefácio ao livro de Aichorn, de 1925, já discutido anteriormente. Por sua vez, Lacan propõe uma quarta forma de as pessoas se relacionarem entre si: fazer desejar. Ou seja, os discursos recobrem essas três atividades - mais a quarta, ditada por Lacan -, relacionadas por Freud como impossíveis, por isso os quatro discursos se referem a impossibilidades.

Ele estabelece inicialmente quatro formas de o sujeito produzir discurso: o do Mestre, o da Histérica, o Universitário e o do Analista. Consistem na disposição ordenada das letras que constituem uma cadeia falada: S1, S2, S, a; em lugares fixos: o agente, a verdade, o outro e a produção, sendo que a estrutura do discurso é definida a partir da dominância do termo escrito no lugar de agente. As setas são indicativas da circulação entre os termos do matema. 
FIGURA 1 - OS QUATRO DISCURSOS CONFORME LACAN

Discurso do Senhor

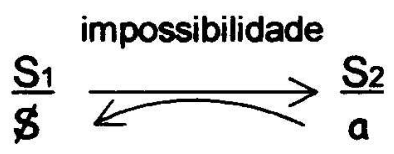

Discurso da Histérica

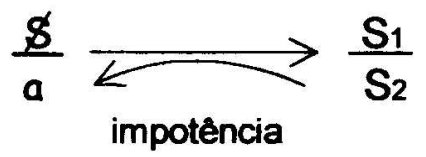

Discurso da Universidade

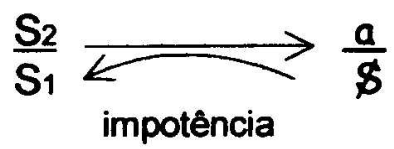

FONTE: O Seminário Livro 17 (1969-1970).

Em outro momento, Lacan reforça a mutação sofrida no discurso do mestre que adquire um "estilo capital". (LACAN, 1969-1970, p. 160). No entanto, somente em 1972, numa conferência em Milão, o quinto discurso é matematizado com o nome de Discurso do Capitalista:

$$
\downarrow \frac{\mathrm{S}}{\mathrm{S}_{1}} \underline{\mathrm{S}}_{2 \downarrow} \mathrm{a}
$$

Sobre essa fórmula, Lacan alerta que há uma inversão entre o $\mathrm{S}_{1}$ e $\mathrm{S}$ barrado:

Uma pequenina inversão... é suficiente para que funcione sem encontrar nenhum obstáculo, não pode funcionar melhor, mas justamente funciona rápido demais, isso se consome, isso se consome tão bem que isso se gasta. (LACAN, 1972, p. 8).

Faremos de modo bem sucinto a descrição do discurso da Histérica e do Analista para que o leitor possa vislumbrar as contribuições de Lacan a respeito 
do tema e advertimos o leitor que iremos nos deter de modo mais aprofundado na questão dos discursos do mestre, do universitário e do capitalista, na sua relação com a educação.

O discurso da Histérica é entendido como aquele que efetivamente produz um saber. Na condição de agente, encontramos o sujeito cindido que dirige ao outro um apelo, que esse saiba o que lhe causa angústia e sofrimento, buscando algo que o alivie. Assim, o saber é produzido, porém, é um saber que fica afastado daquele que o produziu, pois se trata do saber sobre a verdade - a castração do Outro. Eis por que esse discurso interroga o saber e a mestria. Trata-se de um saber que sucumbe ao recalque, mas pode ter outros destinos.

Assim, se o discurso da Histérica é aquele que produz o saber, poderíamos aproximá-lo do que é próprio da ciência, como lugar de fabricação de saberes, em que o dito sujeito cientista não conta muito em suas pesquisas ou descobertas. Isto é, mesmo que um saber seja produzido, o que fica como não sabido, é o $a$ como causa do desejo na posição de verdade. Aqui temos aquele (outro) que é convocado pelo agente na condição de Outro, porém, a cada tentativa de sustentar essa potência sucumbe ao fracasso.

Já o discurso do Analista permitiu a Lacan afirmar que seu avesso constituiria o discurso do Mestre. No discurso em questão, o analista é aquele que ocupa o lugar de agente, porém, não o faz nem na condição de mestre nem por meio de seu saber suposto e tampouco na sua pele de sujeito.

O agente aqui é o resto, ou seja, o objeto perdido, causa do desejo, que fazendo funcionar seu saber como verdade dirige-se ao outro, esse sim na condição de sujeito, e exige dele a produção de seu próprio saber, de seu próprio S1: "[...] ou seja, operar no sujeito um movimento de ressignificação de sua castração simbólica, de reposicionamento do significante fálico, primordialmente recalcado". (ALMEIDA, 2002, p. 103). Tanto para agente quanto para agenciado, o Outro é despersonalizado e submetido à barra que evidencia o impossível.

\section{A educação no discurso do mestre}

Sobre o discurso do Mestre, podemos defini-lo como aquele em que o agente, na condição de detentor do saber, convoca o outro como escravo, exigindo que trabalhe muito e lhe entregue o fruto do seu suor, isto é, que o satisfaça. É o discurso por excelência da constituição do sujeito, pois se trata de manter-se alienado ao outro como condição de subjetivação, supondo no Mestre o saber sobre si. Pelo lado do Mestre, é o outro que detém seu gozo, pois sabe como 
fazê-lo gozar. Assim, o Senhor - a mãe, o professor, o governante, o pai - depende do Escravo - o filho, o aluno, o súdito. É também reconhecido como discurso do inconsciente, já que o sujeito de que se trata é um ser cindido por obra e efeito dos significantes S1 e S2.

No discurso do Mestre, então, o agente funciona como Outro para o agenciado, embora o Mestre reconheça a impossibilidade de tudo saber. Dessa forma, o efeito de encarnação deste Outro barrado sobre o outro é o de ser marcado pela castração, pela falta. Sob tal aspecto, a posição do saber é encarnada, mas supõe o fracasso de todo saber. O Mestre é castrado e, por isso, dirige-se ao outro pedindo que lhe dê o que não tem. Assim, o outro é quem sabe como deixar seu mestre satisfeito.

Ora, contribuir para tal requer do mestre uma posição que contemple um furo de saber, pois é nesse vazio que o ato educativo constitutivo se dá.

Poder suportar subjetivamente a angústia de uma posição discursiva que implica renunciar à onipotência narcísica e aos ideais de grandeza e de perfeição, em fazer semblante de saber, ocupando o lugar de Mestre, eu diria de Mestre barrado, para que o ensino e a transmissão sejam possíveis e realizáveis. (ALMEIDA, 2002, p. 105).

Mesmo que barrado - e talvez por isso mesmo - o educador nesse discurso é o mestre que encarna as insígnias da instituição, investido também pela autorização parental para exercer essa função junto aos alunos. Dele não se espera um saber catedrático, mas que saiba fazer o outro saber o que fazer.

Balizar a educação a partir do discurso do Mestre impõe considerar que há tanto no lugar do educador - agente - quanto do educante - outro - um saber que opera, um saber sobre o impossível de tudo saber.

\section{A educação no discurso universitário}

Por sua vez, o discurso Universitário é aquele em que, na condição de agente, está o saber despersonalizado do mestre como saber absoluto. Ao colocar o saber na posição de Senhor, dirige-se ao outro como pequeno ser, como mero objeto(a), que, espantado com a avalanche de conhecimento, divide-se produzindo o dito "sujeito da ciência", dela excluído. 
Para Lacan, o discurso do Mestre é desnudado pelo discurso Universitário, que torna o alcançar a verdade impossível. Assim, o mestre moderno é aquele que não é, posto que em seu lugar está o saber! "Não pensem que o mestre está sempre aí. O que permanece é o mandamento, o imperativo categórico 'continua a saber" ". (LACAN, 1969-1970, p. 99). Ora, alguém que pretende ocupar o lugar de um saber sem falhas, totalizante, de colonizador do real, convida o outro a permanecer numa condição de assujeitamento e alienação absolutos. Ao submeter-se a esse imperativo categórico de continuar a saber sempre mais, toda questão em direção à verdade será silenciada.

No discurso Universitário, exige-se que o professor-educador "constitua o sujeito da ciência com sua própria pele". (LACAN, 1969-1970, p. 99). Esse sujeito em sua produção não pode, de maneira alguma, perceber-se como senhor do saber.

O sujeito afanisado, então, é por excelência o excluído pela ciência, já que sua verdade - subjetiva - é substituída pelo imperativo de um saber-tudo. O discurso do Mestre Moderno é, portanto, o discurso Universitário. Pois, na posição de agente, encontramos o saber científico e não mais o Mestre. A autoridade magistral - o Mestre - é o fundamento que precisa ser recalcado, para dar lugar ao tudo que o saber comporta, colocando S2 na posição de agente.

O educador surge como prestigiador do saber e se apresenta, de preferência, como cientista ou pesquisador. Relativamente a tudo que a ciência se ocupa, deve ocupar uma condição de objeto e exigir que o sujeito dividido não tenha outra condição a não ser a de excluído.

A condição de que a educação deslize para o discurso Universitário é de que a ciência ocupe o lugar do Mestre, dessubjetivando tanto o educador quanto o educando. Quando o discurso da educação começa a se dar nos moldes do discurso Universitário, significa que o sujeito em sua verdade desaparece em prol do todo-saber e do saber sem furos.

Como resultado dessa exclusão subjetiva, vemos que alguns educadores, diante do saber que a ciência produz e oferece - por meio dos estagiários das universidades com seus treinamentos e capacitações -, acabam por fazer uso de sua própria "intuição", pois, por mais que depositem crédito nesse saber, dele desconfiam já que não o entendem. Outros, porém, acabam por "rezar pela cartilha" integralmente e tratam de velar o que quer que escape aos parâmetros científicos.

Se uns respondem ao discurso Universitário, histericizando-o - quanto mais saber se produzir mais se desconfia disso, pois isso não responde à "verdadeira" questão (do desejo) -, outros, porém, deixam-se tomar como instrumentos do saber científico e mantêm a prevalência desse discurso. Mas, cada resposta dada por essa ciência é insuficiente para saciar o desejo do dito corpo docente, ou melhor, doente do saber. O professor é substituído pelo saber. 
O educador, quer seja uma mãe, um pai ou o professor que busque ocupar um lugar de saber todo, tem como consequência a alienação absoluta do outro que se pretende educar.

Se o discurso universitário, como seu nome indica, articula a possível relação entre saber e educar, isto é, há alguém que sabe, detém o poder do saber absoluto e portanto educa outros que estariam em posição de ser "educados", entraria em contradição com o princípio do impossível por meio do qual Freud definiu a tarefa de educar. Deixaria de lado, sem reconhecer, o que resta de toda a relação de ensino, de toda a relação do sujeito ao Outro: o objeto $a$. (NANCLARES, apud VEGH, 2001, p. 114).

\section{A educação no discurso do capitalista}

Como descrito anteriormente, o reposicionamento de $\mathrm{S}$ barrado e $\mathrm{S}_{1}$ no lugar de agente e da verdade, respectivamente, bem como as setas apontando para baixo, Lacan os entenderá como o discurso do Mestre Moderno, ou o Do Capitalista, em que o sujeito determina a própria verdade e indica o obscurecimento da dimensão de castração. Desse processo, duas consequências se evidenciam: o risco de que o impossível, o fracasso desapareça, na medida em que o objeto - gadget - se torna possível e, portanto, fabricável; e a extinção do sujeito na condição de enunciação, restando-lhe sua afirmação em torno exclusivamente dos enunciados e produzindo um rechaço da dimensão da impossibilidade estrutural.

Assim, a fabricação de objetos sem fundo de ausência subverte a ideia de $\boldsymbol{a}$ como causa do desejo, mas institui o gadget como causa de necessidade e de fascínio em torno da promessa de satisfação total. Por isso, o uso cínico da renegação do gozo é característica desse discurso, o que produz ou um reforçamento do fantasma ou até mesmo sua implosão.

Voltolini (2005) tece interessantes comentários sobre a educação e o discurso do Capitalista. Para ele, uma proposta de laço social que regride do desejo para a necessidade e traz o ícone do "tudo é possível" implica impacto sobre as práticas de palavra, pois, dificilmente suportar-se-á que não haja uma palavra justa e definitiva, em que o discurso se comporte com regularidade e precisão cirúrgica para definir o objeto.

Nesse aspecto, as práticas e saberes constituídos evidenciam a primazia da técnica, do "como fazer", em detrimento do "fazer para quê". 
Se a educação é considerada uma ciência humana, não escapa à pregnância da tecnociência, em que o professor assume de vez sua função de tecnocrata. Ele é substituído pelo mercado.

Ter o mercado como agente no laço entre o sujeito e a produção de conhecimento redimensiona o lugar de ambos. A aquisição de conhecimento deixa de estar do lado da construção de saberes e opera como ferramenta para competir por um lugar no mercado: "Pensei ter indicado [...] que o que se opera entre o discurso do senhor antigo e do senhor moderno, que se chama capitalista, é uma modificação no lugar do saber". (LACAN, 1969-1970, p. 29). O saber conferido ao escravo desaparece e nesse surge um saber de senhor. É por isso que, para Lacan, o escravo não faz nada mais do que trocar de senhor.

Se no discurso do Mestre, o Mestre ocupa lugar de agente, e no discurso Universitário, o saber está como agenciador, no discurso do Capitalista, é S barrado que está na condição de agente e que mostra uma nova tirania do saber, pois esse novo senhor é o capital que opera sobre os laços discursivos em seu ofício:

De onde sai isso, o fato de que haja nesse lugar um significante de senhor? Pois este é precisamente o $\mathrm{S}_{2}$ do senhor, mostrando o cerne do que está em jogo na nova tirania do saber. Isto é o que torna impossível que nesse lugar apareça, no curso do movimento histórico, o que cabe à verdade. [...]. O sinal da verdade está agora em outro lugar. Ele deve ser produzido pelos que substituem o antigo escravo, isto é, pelos que são eles próprios produtos, como se diz, consumíveis tanto quanto os outros. Sociedade de consumo, dizem por aí. Material humano, como se enunciou um tempo - sob os aplausos de alguns que ali viram ternura. (LACAN, 1969-1970, p. 30, grifos do autor).

Transformar a educação num bem de consumo retira desse ato sua condição de dispositivo simbólico de engendramento de um ser de linguagem capaz de inscrever seu lugar na cultura. Dá-lhe o estatuto de mais um gadget ofertado pela feira acadêmica de escolas e universidades, em que a formação não mais se sustenta no ideal de "ser alguém na vida", mas na fantasia de "ter a vida de alguém", em que o ponto de identificação se fixa no bem e não no ser. Isto é, a referência fálica não está em ser um médico ou alfabetizado, mas a de que essa competência adquirida nos bancos - e berços - escolares dê condições de fazer o mercado funcionar.

Torna-se preocupante que a educação e o ato educativo passem a ser entendidos apenas a partir de um "furor pedagógico". 


\section{Conclusão}

Nas lições que antecedem o fim do Seminário 17-O avesso da psicanálise, Lacan tratou de justificar sua conceituação dos discursos. Ao fazer referência aos três impossíveis - governar, educar e analisar -, aos quais acrescenta o fazer desejar, ele acentuou o caráter impossível dessas funções. O que aí surge como impossível? O Real.

É na etapa em que ocorreu de se definir que é impossível demonstrar-se como verdadeiro o registro de uma articulação simbólica que o real se situa, que o real se define como o impossível. Eis o que pode servir-nos para medir nosso amor pela verdade - e também o que pode nos fazer tocar de perto por que governar, educar, analisar também, e - por que não? - fazer desejar, para completar com uma definição o que caberia ao discurso da histérica, são operações que, falando propriamente, são impossíveis. (LACAN, 1969-1970, p. 164-165).

Assim, não se pode governar, educar, analisar e fazer desejar o Real. Isso torna-se tarefa impossível.

Ao tocar nessa questão, mesmo que de maneira breve, Melman (2004) indica a que se deve a impossibilidade que caracteriza o governar, o educar e o analisar quando são exercidos da posição de Mestre:

Somos mal governados, mal-educados e não somos bem psicanalisados e, para se produzir alguma mudança, é necessário colocar o impossível no começo, quer dizer, que seja registrado na cultura que aquilo que é nosso motor, nossa fonte de energia é o impossível. (MELMAN, 2004, p. 64).

Ao entendermos o sujeito como aquele que emerge da linguagem e o reconhecemos como falante, é indispensável considerar a quem dirige a fala e de que lugar fala. Sua posição na condição de falante traz efeitos imediatos sobre seu ofício e sobre os laços que cria nesse campo.

Assim, a partir das discussões sobre os discursos, vemos que nos laços estabelecidos entre a educação, as ciências, os educadores e os educandos, o discurso faz giro; nunca permanece numa única modalidade discursiva. Mesmo 
que gire, o que se produz aí é um tipo de marasmo gozante, já que em nenhum desses movimentos o sujeito efetivamente está próximo de sua verdade. Para isso, teríamos de introduzir o discurso do Analista.

Nesse caso, o outro é o quem será reconhecido pelo agente como sujeito cindido e, ao convidá-lo a falar, aposta que possa construir seus significantes mestres, aproximar-se de um saber, que ele detém, mas lhe era desconhecido.

Parece ser essa a novidade que a psicanálise pode introduzir no trabalho com a educação, já que, ao não responder literalmente ao desejo insaciável de saber mais e mais, o analista convoca o educador a falar mais sobre isso que "deixa a desejar", permitindo que esse siga os rastros que seus significantes recalcados deixaram, na construção de um saber sobre si mais legítimo. Dessa forma, o próprio educador pode dialogar com o saber científico que chega por "atacado" nos espaços educacionais. Por último, a relação que se dá entre o educador e seus educantes oferta um pouco àquele o lugar que ao longo dos tempos se vê excluído, a saber, o de Mestre.

Se suspeitamos que os dispositivos discursivos da atualidade - a família ou a escola - perderam sua plasticidade subjetiva e não mais conseguem operar com o não calculável, o não experimentável e o não dizível, uma proposta que vise a oferecer condições de trabalho na educação deve contemplar essas questões. Com isso, tiraríamos o caráter científico dos espaços escolares para então subjetivá-la, sob a evidência de que constituir um lugar educacional exige um lugar para o não saber.

\section{REFERÊNCIAS}

ALMEIDA, S. F. C. Psicanálise e Educação: revendo algumas observações e hipóteses sobre uma (im)possível conexão. In: LAJONQUIÈRE, L.; KUPFER, M. C. (Org.). COLÓQUIO DO LEPSI, 3. Anais... São Paulo: Ipusp, 2002. p. 95-106.

FREUD, S. Análise fragmentária de uma histeria. (Edição Standard Brasileira das Obras Psicológicas Completas de Sigmund Freud) (1901). Rio de Janeiro: Imago, 1976.

FREUD, S. Dinâmica da Transferência. (Edição Standard Brasileira das Obras Psicológicas Completas de Sigmund Freud) (1912). Rio de Janeiro: Imago, 1976.

FREUD, S. Sobre a psicologia escolar. Obras Completas (1914). Rio de Janeiro: Imago, 1976. v. 13.

FREUD, S. Prefácio à juventude desorientada de Aichhorn. In: FREUD, S. Obras Completas (1925). Rio de Janeiro: Imago, 1976. p. 341-6. v. 19. 
FREUD, S. O futuro de uma ilusão. (Edição Standard Brasileira das Obras Psicológicas Completas de Sigmund Freud) (1927). Rio de Janeiro: Imago, 1976.

FREUD, S. Análise terminável e interminável. (Edição Standard Brasileira das Obras Psicológicas Completas de Sigmund Freud, v. 23) (1937). Rio de Janeiro: Imago, 1976.

FREUD, S. Mal-estar na civilização. Obras completas (1930). Rio de Janeiro: Imago, 1976.

KUPFER, M. C. M. Freud e a educação. São Paulo: Scipione, 1989.

KUPFER, M. C. M. et. al. A produção brasileira no campo das articulações entre psicanálise e educação a partir de 1980. Estilos clin., São Paulo, v. 15, n. 2, p. 284-305, dez. 2010. Disponível em: <http://pepsic.bvsalud.org/scielo.php?script=sci_arttext\&pid=S $141571282010000200002 \& \operatorname{lng}=$ pt\&nrm=iso $>$. Acesso em: 07 fev. 2016.

LACAN, J. O seminário Livro 17 (1969-1970). Rio de Janeiro: Jorge Zahar, 1992.

LACAN, J. O seminário Livro 18 (1971). Recife: Centro de Estudos Freudianos de Recife, 1996, circulação interna.

LACAN, J. Du discours psychanalytique (1972). In: Lacan en Italie, Edition La Salamandra Disponível em: <www.pros.orange.fr/espace.freud/topos/psycha/psysem/italie.htm>.

LAJONQUIÈRE, L. de. A Infância e a educação nos tempos sombrios do narcisismo. In: COLÓQUIO FRANCO-BRASILEIRO, Anais... Universidade de Paris XIII, 2001.

MARIOTTO, R. M. M. Cuidar, educar e prevenir: as funções da creche na subjetivação de bebês. São Paulo: Escuta, 2009.

MELMAN, C. A neurose obsessiva. Rio de Janeiro: Companhia de Freud, 2004.

NUNES, M. R. M. Psicanálise e educação: pensando a relação professor-aluno a partir do conceito de transferência. In: COLOQUIO DO LEPSI IP/FE-USP, 5., 2004, São Paulo. Proceedings online... Disponível em: <http://www.proceedings.scielo.br/scielo. php?script $=$ sci_arttext\&pid=MSC0000000032004000100040\&lng=en\&nrm=abn $>$. Acesso em: 07 fev. 2016.

QUINET, A. As novas formas do sintoma em medicina. Ágora - Estudos em teoria psicanalítica, Contra Capa, RJ, jul./dez. 1999.

VEGH, I. Os discursos e a cura. Rio de Janeiro: Cia de Freud, 2001.

VOLTOLINI, R. Conferência: psicanálise, educação e contemporaneidade. Curitiba: APC, 03/12/2005. Material não publicado.

Texto recebido em 17 de dezembro de 2016. Texto aprovado em 03 de janeiro de 2017. 